\title{
EQUITY
}

Vol. 22, No.2, 2019, 215-238

DOI: $10.34209 /$ equ.v22i 2.932

P-ISSN 0216-8545 | E-ISSN 2684-9739

Diunggah : Juli 2019

Diterima : Januari 2020

Dipublikasi : Januari 2020

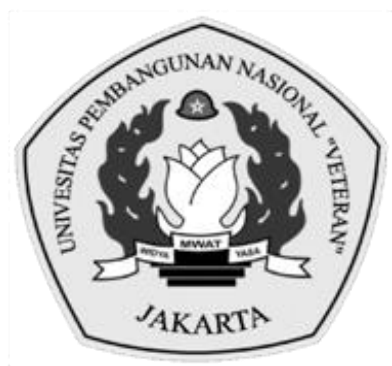

\section{DETERMINAN PENGUNGKAPAN CORPORATE SOCIAL RESPONSIBILITY PERUSAHAAN DI BURSA EFEK INDONESIA}

\author{
Haryanti Hasanah ${ }^{1 *}$, Astrid Rudyanto ${ }^{2}$ \\ 1'hasanahharyanti@yahoo.com,2astrid.rudyanto@tsm.ac.id \\ 1,2Trisakti School of Management \\ *Penulis Korespondensi
}

\begin{abstract}
Abstrak
Tujuan penelitian ini adalah untuk menguji faktor-faktor yang mempengaruhi pengungkapan corporate social responsibility (perempuan pada dewan direksi, ukuran direksi, kepemilikan publik, ukuran perusahaan, profitabilitas, leverage, umur perusahaan, dan likuiditas). Populasinya adalah perusahaan manufaktur yang terdaftar pada Bursa Efek Indonesia dari periode 2014 hingga 2016. Penelitian ini menggunakan 99 sampel dipilih dengan prosedur purposive sampling, sehingga data berjumlah 297. Hipotesis diuji menggnakan metode multiple regression. Bukti empirik dari penelitian ini mengindikasikan bahwa ukuran direksi, ukuran perusahaan, dan leverage memiliki dampak statistik terhadap pengungkapan corporate social responsibility. Perempuan pada dewan direksi, kepemilikan public, profitabilitas, umur perusahaan, likuiditas tidak memiliki dampak terhadap corporate social responsibility.
\end{abstract}

Kata Kunci: Pengungkapan Corporate Social Responsibility; Ukuran Dewan Direksi; Ukuran Perusahaan; Leverage

\begin{abstract}
The purpose of this research is to examine the factors affected corporate social responsibility disclosure (women on board, board size, public ownership, firm size, profitability, leverage, firm age and liquidity). The population are manufacturing firms listed in Indonesia Stock Exchange (IDX) from the period of 2014 to 2016. This research uses 99 samples selected by purposive sampling procedures, thus totaled 297 data. Hypothesis were tested using multiple regression method. The empirical evidence of this research indicate that board size, firm size and leverage have statistically influence toward corporate social responsibility disclosure. Women on board, public ownership, profitability, firm age and liquidity have no influence toward corporate social responsibility disclosure.
\end{abstract}

Keywords: Corporate Social Responsibility Disclosure; Board Size; Firm Size; Leverage

\section{PENDAHULUAN}

Sebagai negara berkembang, Indonesia terus berusaha mencapai pertumbuhan ekonomi di berbagai sektor yang dimilikinya. Dari sisi pertumbuhan, selama tahun 2016 pertumbuhan industri di Indonesia mencapai angka 4,4\% (Audrine, 2017). Sejalan dengan perkembangan usahanya perusahaan harus 
beradaptasi dengan masyarakat lokal dalam rangka membina hubungan kerja sama dengan stakeholder. Kegiatan untuk membina hubungan ini pada umumnya hanya bersifat derma (charity). Hal ini seolah menampakkan bahwa perusahaan melaksanakan kewajibannya sebagai aktivitas rutin belaka tanpa adanya kedalaman nilai hubungan sosial.

Untuk menangani hal ini, pemerintah selaku regulator telah menetapkan Undang-Undang Nomor 40 Tahun 2007 tentang Perseroan Terbatas, UndangUndang No. 25 Tahun 2007 dan Peraturan Pemerintah Nomor 47 Tahun 2012. Berdasarkan Undang-Undang dan Peraturan Pemerintah tersebut, perusahaan akan melakukan dan mengungkapkan informasi aktivitas yang berhubungan dengan pelaksanaan tanggung jawab sosial, atau yang biasa disebut dengan Corporate Social Responsibility (CSR).

Berdasarkan penelitian yang dilakukan oleh Rusmanto et al. (2014) perusahaan yang menduduki posisi teratas dalam pengungkapan tanggung jawab sosial ialah PT. Bakrieland Development Tbk. Perusahaan tersebut meraih beberapa penghargaan salah satunya Best Indonesian Green CSR Award yang diselenggarakan oleh majalah bisnis dan CSR. Namun keberhasilan PT. Bakrieland Development Tbk. dalam hal tanggung jawab sosial ditengarai sebagai akibat dari bencana lumpur Lapindo pada tahun 2006. Kerusakan parah dan kerugian besar yang harus ditanggung masyarakat akibat aktivitas operasional perusahaan tersebut membuat citra perusahaan turun di mata para stakeholdernya, sehingga untuk mengembalikan citra tersebut perusahaan melakukan banyak aktivitas CSR pada tahun-tahun setelahnya. Hal ini menimbulkan pertanyaan mengenai faktor yang menyebabkan tingkat pengungkapan tanggung jawab sosial perusahaan.

Penelitian sebelumnya telah meneliti mengenai faktor yang meningkatkan tingkat pengungkapan tanggung jawab sosial perusahaan. Rudyanto (2018) meneliti pengaruh faktor mekanisme internal (ukuran dewan komisaris, lama masa kerja dewan, wanita dalam dewan) dan mekanisme eksternal (profitabilitas, umur perusahaan, ukuran perusahaan) terhadap pengungkapan tanggung jawab sosial perusahaan. Penelitian ini menunjukkan bahwa jika faktor mekanisme internal dan faktor mekanisme eksternal diuji secara terpisah maka ukuran dewan komisaris, profitabilitas, ukuran perusahaan mempengaruhi pengungkapan tanggung jawab sosial perusahaan. Namun jika faktor mekanisme internal dan eksternal diuji bersama maka ukuran dewan komisaris, wanita dalam komisaris, umur perusahaan, profitabilitas, ukuran perusahaan mempengaruhi pengungkapan tanggung jawab sosial perusahaan. Hal ini menunjukkan bahwa mekanisme internal dan eksternal harus diuji secara bersama untuk melihat pengaruhnya terhadap pengungkapan tanggung jawab sosial perusahaan. Penelitian lainnya juga menunjukkan bahwa faktor-faktor ini harus diuji bersama untuk melihat pengaruh faktor-faktor ini terhadap pengungkapan tanggung jawab sosial perusahaan (Zhang et al. 2012, Giannarakis 2013, Khan et al. 2013, Rusmanto et al. 2014, Herawati 2015).

Permasalahan dalam penelitian ini yaitu apakah komposisi wanita dalam dewan komisaris, ukuran dewan komisaris, kepemilikan publik, ukuran perusahaan, profitabilitas, leverage, usia perusahaan, dan likuiditas berpengaruh terhadap pengungkapan tanggung jawab sosial perusahaan. Berdasarkan masalah penelitian tersebut, maka tujuan penelitian ini yaitu mendapatkan bukti empiris pengaruh komposisi wanita dalam dewan komisaris, ukuran dewan komisaris, 
kepemilikan publik, ukuran perusahaan, profitabilitas, leverage, usia perusahaan, dan likuiditas terhadap pengungkapan tanggung jawab sosial perusahaan. Penelitian ini menambahkan variable leverage, kepemilikan publik, dan likuiditas serta mengeluarkan variabel masa kerja dewan dari penelitian Rudyanto (2018). Masa kerja dewan dikeluarkan karena Rudyanto (2018) menemukan bahwa variabel ini tidak berpengaruh pada pengungkapan tanggung jawab sosial perusahaan. Penelitian ini menambahkan leverage dan likuiditas karena leverage dan likuiditas juga merupakan variabel mekanisme eksternal (visibilitas) yang dapat mempengaruhi pengungkapan tanggung jawab sosial perusahaan (Rusmanto et al. 2014). Kepemilikan publik menunjukkan mekanisme internal berupa pengawasan dari investor (Khan et al. 2013). Penelitian ini terdiri dari pendahuluan, kerangka teoritis dan pengembangan hipotesis, metoda penelitian, analisis dan pembahasan serta penutup.

\section{TINJAUAN PUSTAKA}

\section{Teori Legitimasi}

Legitimasi adalah persepsi umum atau asumsi bahwa tindakan entitas harus tepat dan sesuai dengan sistem sosial yang dibagun dengan norma, nilai-nilai, keyakinan, dan definisi di dalamnya (Suchman 1995). Legitimasi dianggap penting bagi perusahaan karena legitimasi masyarakat, yang juga berperan sebagai stakeholder, kepada perusahaan menjadi salah satu faktor yang strategis bagi perkembangan perusahaan ke depan. Salah satu strategi untuk membangun dan mempertahankan legitimasi dari para stakeholder dan masyarakat adalah dengan melaksanakan pengungkapan tanggung jawab sosial, dimana dengan pelaksanaan tersebut diharapkan keinginan dari masyarakat dapat terakomodasi sehingga akan menghasilkan hubungan yang harmonis yang mengakibatkan perusahaan dapat memperoleh legitimasi dari masyarakat dan mencapai keberlanjutan atau kelestarian perusahaannya (Astuti dan Trisnawati 2015). Dapat disimpulkan bahwa pengungkapan tanggung jawab sosial perusahaan berdasarkan teori stakeholder menjadi media untuk mendapatkan legitimasi masyarakat yang merupakan bagian dari stakeholder itu sendiri.

\section{Teori Stakeholder}

Ross et al. $(2015,14)$ mendefinisikan stakeholder sebagai orang lain selain pemegang saham atau kreditur yang berpotensi memiliki klaim atas arus kas perusahaan. Kelompok tersebut juga akan mencoba untuk melakukan kontrol atas perusahaan yang mungkin dapat merugikan pemilik. Teori stakeholder menjelaskan bahwa perusahaan akan memaksimalkan usahanya agar bisa mendapat dukungan penuh dari stakeholder, dan salah satu caranya adalah dengan mengungkapkan tanggung jawab sosial perusahaan. Terkait hubungan antara teori legitimasi dengan teori stakeholder, teori legitimasi mengisyaratkan bahwa dalam rangka menjaga atmosfer bisnis yang kondusif, dibutuhkan legitimasi stakeholder, yaitu kongruen atau kesesuaian antara keberadaan perusahaan dengan harapan (expectation) masyarakat dan lingkungan (O'Donovan, 2002). Teori stakeholder mempertegas bahwa keberadaan perusahaan di tengah lingkungan tidak dapat dilepaskan dengan 
stakeholder, sebab mereka adalah para pihak yang memiliki kepentingan secara langsung maupun tidak langsung terhadap perusahaan serta dipengaruhi dan mempengaruhi perusahaan. Untuk itu, survival perusahaan sangat bergantung pada sejauh mana perusahaan memperoleh legitimasi dari stakeholder.

\section{Komposisi Wanita dalan Dewan Komisaris dan Pengungkapan Tanggung Jawab Sosial Perusahaan}

Komposisi wanita dalam jajaran dewan komisaris dapat digunakan sebagai proxy dalam mengidentifikasi variasi dewan komisaris (Carter et al. 2003). Wanita yang dianggap lebih memiliki kepekaan terhadap sesama, dipandang sebagai faktor pemicu luasnya pengungkapan tanggung jawab sosial perusahaan. Penelitian menunjukkan bahwa wanita lebih beretika (Atakan et al 2008) dan memiliki jiwa sosial yang lebih tinggi (Smith et al. 2001). Karena wanita lebih beretika, mereka akan lebih memperhatikan kepentingan pemangku kepentingan sehingga akan melakukan tanggung jawab sosial dan mengungkapkannya. Penelitian yang dilakukan Rusmanto et al. (2014), Giannarakis (2013) dan Khan (2010) menghasilkan bukti empiris bahwa komposisi wanita dalam dewan komisaris tidak memiliki pengaruh terhadap pengungkapan tanggung jawab sosial perusahaan. Hasil ini berlawanan dengan penelitian Kaspereit et al. (2016), Sundarasen et al. (2015), Kilic et al. (2014), Pamies (2013), dan Zhang et al. (2012), yang menyatakan bahwa komposisi wanita dalam dewan komisaris berpengaruh positif terhadap pengungkapan tanggung jawab sosial perusahaan.

Ha1: Komposisi Wanita dalam Dewan Komisaris memiliki pengaruh terhadap Pengungkapan Tanggung Jawab Sosial Perusahaan.

\section{Ukuran Dewan Komisaris dan Pengungkapan Tanggung Jawab Sosial Perusahaan}

Rusmanto et al. (2014) menyatakan bahwa Board of Director atau yang di Indonesia disebut sebagai Dewan Komisaris adalah mereka yang memiliki wewenang untuk mengawasi pengelolaan perusahaan yang dilakukan oleh manajemen. Dewan komisaris adalah pihak yang mengawasi pelaksanaan kegiatan operasional dan mempertanggungjawabkannya kepada publik (dalam bentuk laporan) sebagai pihak yang mempercayakan dewan komisaris sebagai pengawas perusahaan. Semakin besar ukuran dewan komisaris, semakin banyak keahlian berbeda yang dimiliki oleh dewan komisaris untuk mengawasi tanggung jawab sosial perusahaan. Hal ini mengakibatkan tanggung jawab sosial yang dilaporkan semakin luas. Giannarakis (2013), Deitiana (2015), Ling dan Sultana (2015), Oktariani (2013), Priatana dan Yustian (2011), Utami dan Rahmawati (2010), serta Siregar dan Bachtiar (2010) dalam penelitiannya mengungkapkan bahwa semakin besar jumlah dewan komisaris, semakin luas pula pengungkapan tanggung jawab sosial perusahaan. Hasil berbeda dibuktikan oleh Septiana dan Fitria (2014), Dermawan dan Detiana (2014), Badjuri (2011), dan Yuliana et al. (2008). Dalam penelitiannya, mereka menyatakan bahwa ukuran dewan komisaris tidak berpengaruh terhadap pengungkapan tanggung jawab sosial perusahaan.

Ha2: Ukuran Dewan Komisaris memiliki pengaruh terhadap 
Pengungkapan Tanggung Jawab Sosial Perusahaan

\section{Kepemilikan Publik dan Pengungkapan Tanggung Jawab Sosial Perusahaan}

Kepemilikan publik adalah saham perusahaan yang dimiliki oleh masyarakat yang ada di Indonesia. Semakin besar kepemilikan publik, semakin besar kekuatan publik untuk meminta pertanggungjawaban perusahaan atas tanggung jawab sosial. Hal ini meningkatkan luasnya pengungkapan tanggung jawab sosial perusahaan. Penelitian yang dilakukan oleh Khan et al. (2013), Rahayu dan Anisyukurillah (2015) serta Sriayu dan Mimba (2013) mengungkapkan bahwa kepemilikan publik atas perusahaan berpengaruh positif terhadap pengungkapan tanggung jawab perusahaan. Deitiana (2015), Dermawan dan Deitiana (2014), Oktariani (2013), Nur dan Priantinah (2012), Yusuf (2011) dan Badjuri (2011) menunjukkan bahwa kepemilikan publik terhadap perusahaan tidak memiliki pengaruh terhadap pengungkapan tanggung jawab sosial perusahaan.

Ha3: Kepemilikan Publik memiliki pengaruh terhadap Pengungkapan Tanggung Jawab Sosial Perusahaan.

\section{Ukuran Perusahaan dan Pengungkapan Tanggung Jawab Sosial Perusahaan}

Umumnya, perusahaan besar (total aset tinggi) mengungkapkan informasi yang lebih banyak daripada perusahaan kecil karena perusahaan besar merupakan emiten yang banyak disoroti oleh publik (Astuti dan Trisnawati 2015). Menurut teori legitimasi, tingkat visibilitas yang tinggi mendorong perusahaan untuk mengungkapkan tanggung jawab sosial perusahaan. Tan et al. (2016), Plorensia dan Hardiningsih (2015), Herawati (2015), Dermawan dan Deitiana (2014), Indraswari dan Astika (2014), Giannarakis (2013), Rahman et al. (2011), Utami dan Rahmawati (2010), serta Haniffa dan Cooke (2005) mengungkapkan secara empiris bahwa ukuran perusahaan berpengaruh positif terhadap pengungkapan tanggung jawab sosial perusahaan. Namun, penelitian yang dilakukan oleh Rusmanto et al. (2014), Pradnyani dan Sisdyani (2015), Oktariani dan Mimba (2014), serta Laksmitaningrum dan Purwanto (2013) menyatakan bahwa ukuran perusahaan tidak berpengaruh terhadap pengungkapan tanggung jawab sosial perusahaan.

Ha4: Ukuran Perusahaan memiliki pengaruh terhadap Pengungkapan Tanggung Jawab Sosial Perusahaan.

\section{Profitabilitas dan Pengungkapan Tanggung Jawab Sosial Perusahaan}

Profitabilitas merupakan hubungan antara pendapatan dan biaya yang dihasilkan dengan menggunakan aset perusahaan, baik aset lancar maupun aset tetap, dalam kegiatan produktif (Gitman dan Zutter 2015, 655). Menurut teori legitimasi, semakin besar profitabilitas perusahaan, semakin tinggi tingkat visibilitas perusahaan sehingga perusahaan juga didorong untuk mengungkapkan tanggung jawab sosial dengan lebih luas. Herawati (2015), Ling dan Sultana (2015), Dewi dan Keni (2013), Puryati (2013), Nurkhin (2010), serta Haniffa dan Cooke (2005) yang menyatakan bahwa profitabilitas berpengaruh positif terhadap pengungkapan tanggung jawab sosial perusahaan. Namun Rusmanto et al. (2014), Sulistyawati et al. (2016), Rahayu dan Anisyukurillah (2015), Dermawan dan 
Deitiana (2014), Oktariani dan Mimba (2014), serta Rahman et al. (2011) mengungkapkan bahwa profitabilitas tidak berpengaruh terhadap pengungkapan tanggung jawab sosial perusahaan.

Ha5: Profitabilitas memiliki pengaruh terhadap Pengungkapan Tanggung Jawab Sosial Perusahaan.

\section{Leverage dan Pengungkapan Tanggung Jawab Sosial Perusahaan}

Leverage menggambarkan jumlah pendanaan yang berasal dari utang dalam struktur modal yang dimiliki suatu perusahaan (Subramanyam 2014, 565). Pengaruh leverage terhadap pengungkapan tanggung jawab sosial perusahaan tergantung pada pemangku kepentingan yang lebih peduli pada tanggung jawab sosial. Jika kreditur lebih peduli pada tanggung jawab sosial maka semakin besar jumlah leverage, semakin besar pengungkapan tanggung jawab sosial perusahaan. Jika pemegang saham lebih peduli pada tanggung jawab sosial maka semakin besar jumlah leverage, semakin rendah pengungkapan tanggung jawab sosial perusahaan. Ling dan Sultana (2015), Chan et al. (2013), dan Puryati (2013), yang menyatakan bahwa leverage berpengaruh positif terhadap pengungkapan tanggung jawab sosial perusahaan. Khan et al. (2013), Nur dan Priantinah (2012) dalam penelitiannya menyatakan bahwa leverage berpengaruh negatif terhadap pengungkapan tanggung jawab sosial perusahaan. Namun, Rusmanto et al. (2014), Sulistyawati et al. (2016), Dermawan dan Deitiana (2014), Dewi dan Keni (2013), Laksmitaningrum dan Purwanto (2013), Badjuri (2011), Rahman et al. (2011), Khan (2010), serta Haniffa dan Cooke (2005) menyatakan bahwa leverage tidak berpengaruh terhadap pengungkapan tanggung jawab sosial perusahaan. Penelitian di atas tidak sejalan dengan

Ha6: Leverage memiliki pengaruh terhadap Pengungkapan Tanggung Jawab Sosial Perusahaan.

\section{Usia Perusahaan dan Pengungkapan Tanggung Jawab Sosial Perusahaan}

Usia perusahaan menunjukkan bahwa perusahaan tetap bertahan dan mampu bersaing. Semakin lama usia perusahaan, semakin tinggi tingkat pengungkapan tanggung jawab sosialnya. Hal ini disebabkan karena semakin tua perusahaan, perusahaan tersebut semakin mengerti atas pentingnya legitimasi dari pemangku kepentingan. Legitimasi dari pemangku kepentingan diperoleh dari pengungkapan tanggung jawab sosial perusahaan. Hal ini sejalan dengan penelitian yang dilakukan oleh Khan et al. (2013), Herawati (2015) dan Yusuf (2011). Namun, hal ini tidak didukung oleh penelitian yang dilakukan oleh Oktariani (2013), Dewi dan Keni (2013), Santioso dan Chandra (2012), serta Utami dan Rahmawati (2010). Penelitian tersebut menunjukkan hasil bahwa usia perusahaan tidak berpengaruh terhadap pengungkapan tanggung jawab sosial perusahaan.

Ha7: Usia Perusahaan memiliki pengaruh terhadap Pengungkapan Tanggung Jawab Sosial Perusahaan. 


\section{Likuiditas dan Pengungkapan Tanggung Jawab Sosial Perusahaan}

Likuiditas merupakan kemampuan perusahaan dalam memenuhi kewajiban jangka pendeknya ketika jatuh tempo (Gitman dan Zutter 2015, 119). Tingkat likuiditas menunjukkan kemampuan finansial perusahaan untuk jangka pendek. Pengaruh likuiditas terhadap pengungkapan tanggung jawab sosial perusahaan juga dapat dilihat dari dua sisi. Sisi pertama, jika likuiditas perusahaan tinggi maka perusahaan memiliki kemampuan finansial untuk membiayai kegiatan dan pengungkapan tanggung jawab sosial perusahaan. Sulistyawati et al. (2016), Samsiyah dan Kurnia (2014), Laksmitaningrum dan Purwanto (2013), dan Yusuf (2011) menyatakan bahwa likuiditas memiliki pengaruh positif terhadap pengungkapan tanggung jawab sosial perusahaan. Di sisi lain, jika likuiditas perusahaan tinggi, perusahaan berfokus pada tanggung jawab jangka pendeknya serta dapat mengabaikan tanggung jawab jangka panjang yaitu tanggung jawab sosial perusahaan. Maiyarni et al. (2014) menyatakan bahwa likuiditas berpengaruh negatif terhadap pengungkapan tanggung jawab sosial perusahaan. Sebaliknya, AlAjmi et al. (2015), Kamil dan Herusetya (2012) menyatakan bahwa likuiditas tidak memiliki pengaruh terhadap pengungkapan tanggung jawab sosial perusahaan.

Ha8: Likuiditas memiliki pengaruh terhadap Pengungkapan Tanggung Jawab Sosial Perusahaan.

\section{METODOLOGI PENELITIAN}

\section{Pemilihan Sampel dan Pengumpulan Data}

Populasi yang digunakan dalam penelitian ini adalah seluruh perusahaan yang terdaftar di Bursa Efek Indonesia dari tahun 2014 sampai dengan tahun 2016. Sampel yang digunakan sebanyak 99 perusahaan kategori manufaktur dengan total 297 data yang dipilih menggunakan metode purposive sampling, yaitu pengambilan sampel yang dilakukan dengan menggunakan kriteria tertentu yang dipilih oleh peneliti (Sekaran dan Bougie 2016, 247).

Tabel 1. Prosedur Pemilihan Sampel

\begin{tabular}{clcc}
\hline No. & \multicolumn{1}{c}{ Keterangan } & Perusahaan & Data \\
\hline 1. & $\begin{array}{l}\text { Perusahaan manufaktur yang terdaftar di Bursa Efek Indonesia } \\
\text { secara konsisten selama tahun pengamatan 2014 sampai dengan }\end{array}$ & 135 & 405 \\
$\begin{array}{l}\text { 2016. } \\
\text { Perusahaan manufaktur yang tidak secara konsisten memiliki } \\
\text { periode tutup buku pada 31 Desember selama tahun 2014 sampai } \\
\text { dengan 2016. }\end{array}$ & (4) & (12) \\
$\begin{array}{l}\text { Perusahaan manufaktur yang tidak secara konsisten menyajikan } \\
\text { laporan keuangan dalam mata uang Rupiah selama tahun 2014 } \\
\text { sampai dengan 2016 } \\
\begin{array}{l}\text { Perusahaan manufaktur yang tidak secara konsisten memiliki nilai } \\
\text { ekuitas positif selama tahun 2014 sampai dengan 2016 }\end{array}\end{array}$ & (26) & (78) \\
\hline Total sampel yang digunakan sebagai data penelitian & 99 & 297 \\
\hline
\end{tabular}

Sumber: www.idx.co.id dengan olahan peneliti (2019) 
Penelitian ini menggunakan laporan tanggung jawab perusahaan yang ada di laporan tahunan perusahaan. Seluruh sampel ini memiliki laporan tahunan. Ekuitas perusahaan harus positif agar mendapatkan nilai profitabilitas positif. Perusahaan dengan nilai profitabilitas negatif tidak dapat mengungkapkan tanggung jawab sosial perusahaan karena keterbatasan dana (Rudyanto, 2018).

\section{Model Penelitian}

Penelitian ini menggunakan model penelitian (Rumus 1) sebagai berikut:

Rumus 1. Model Penelitian

$$
\begin{aligned}
& \text { CSRRI }=\alpha+\beta_{1} \text { COMPWD }+\beta_{2} S T A+\beta_{3} R O E+\beta_{4} D T E+\beta_{5} B S I Z E+\beta_{6} P U B+ \\
& \beta_{7} F A G E+\beta_{8} L I Q+\varepsilon \text {. }
\end{aligned}
$$

Dimana:

CSRRI = pengungkapan tanggung jawab social perusahaan

COMPWD = Komposisi wanita dalam dewan komisaris

STA = Ukuran perusahaan

ROE = Profitabilitas

DTE = Leverage

BSIZE = Ukuran dewan komisaris

PUB $\quad=$ Kepemilikan publik

FAGE = Umur perusahaan

LIQ $\quad=$ Likuiditas

\section{Definisi Operasional dan Pengukuran Variabel}

\section{Pengungkapan Tanggung Jawab Sosial Perusahaan}

Proses komunikasi antara perusahaan dengan pihak-pihak lain yang berkepentingan ataupun tidak (stakeholder) atas kegiatan operasional perusahaan (Oktariani 2013). Rusmanto et al. (2014) menggunakan skala rasio dengan metode checklist dengan skala rasio untuk mengukur indeks pengungkapan tanggung jawab sosial atau Corporate Social Responsibility Reporting Index (CSRRI) sebagai berikut:

Rumus 2. Pengukuran Pengungkapan Tanggung Jawab Sosial

$$
\operatorname{CSRRI}=\sum n_{i, t} / n_{j, t}
$$

Jumlah pengungkapan tanggung jawab perusahaan I di tahun $\mathrm{t}$ yaitu $0=$ perusahaan tidak mengungkapkan item CSR, 1 = Perusahaan mengungkapkan item CSR; $n_{j, t}=$ jumlah maksimum dari item CSR yang diungkapkan perusahaan pada tahun t yaitu 41 .

\section{Komposisi Wanita dalam Dewan Komisaris}

Komposisi dewan komisaris merupakan salah satu karakteristik dewan yang berhubungan dengan perannya dalam menjalankan fungsi utamanya, yaitu pengawasan (Priantana dan Yustian 2011). Pengukuran komposisi wanita yang digunakan oleh Rusmanto et al. (2014) adalah menggunakan skala rasio berikut: 
Rumus 3. Pengukuran Kompisis Wanita dalam Dewan

$$
\text { COMPWD }=\frac{\text { Number of Women on Board }}{\text { Board Size }} \times 100 \%
$$

\section{Ukuran Dewan Komisaris}

Ukuran Dewan Komisaris adalah banyaknya jumlah anggota dewan komisaris dalam suatu perusahaan (Nur dan Priantinah 2012). Pengukuran dewan komisaris yang digunakan oleh Giannarakis (2013) menggunakan skala rasio sebagai berikut:

Rumus 4. Pengukuran Jumlah Dewan Komisaris

BSIZE = Number of Directors on The Company Board

\section{Kepemilikan Publik}

Kepemilikan publik merupakan kepemilikan masyarakat umum (bukan institusi yang signifikan) atas saham perusahaan publik (Oktariani 2013). Pengukuran kepemilikan publik yang digunakan oleh Khan et al. (2013) menggunakan skala rasio sebagai berikut:

$$
\begin{array}{r}
\text { Rumus 5. Pengukuran Kepemilikan Publik } \\
\text { PUB = Percentage of Shares Owned by The Public........................ }
\end{array}
$$

\section{Ukuran Perusahaan}

Ukuran perusahaan menggambarkan besar kecilnya suatu perusahaan yang dilihat dari total aset yang dimiliki (Plorensia dan Hardiningsih 2015). Pengukuran untuk ukuran perusahaan adalah menggunakan skala rasio angka total aset sebagaimana dirumuskan menurut Rusmanto et al. (2014) adalah sebagai berikut:

Rumus 6. Pengukuran Kepemilikan Publik

$$
\text { STA }=\text { Ln }(\text { Total Assets })
$$

\section{Profitabilitas}

Profitabilitas menggambarkan kemampuan perusahaan mendapatkan laba melalui semua kemampuan dan sumber yang ada seperti penjualan, kas, modal jumlah karyawan dan sebagainya (Sulistyawati et al. 2016). Dalam penelitian ini profitabilitas diukur oleh Rusmanto et al. (2014) dengan skala rasio menggunakan Return on Equity (ROE). Ross et al. $(2015,53)$ mendefinisikan pengukuran ROE:

Rumus 7. Pengukuran Profitabilitas

$$
\mathrm{ROE}=\frac{\text { Income After Tax }}{\text { Total Equity }}
$$




\section{Leverage}

Tingkat leverage adalah suatu pengukuran untuk melihat kemampuan perusahaan dalam menyelesaikan semua kewajibannya kepada pihak lain (Trisnawati 2014). Leverage atau gearing yang diukur oleh Rusmanto et al. (2014) menggunakan skala rasio dengan rumus yang sama dengan yang dijabarkan oleh Ross et al. $(2015,49)$ yaitu:

$$
\begin{aligned}
& \text { Rumus 8. Pengukuran Leverage } \\
& \text { DTE }=\frac{\text { Total Debt }}{\text { Total Equity }} \ldots \ldots \ldots \ldots \ldots \ldots \ldots \ldots . . . . . . . . . . . .(8)
\end{aligned}
$$

\section{Usia Perusahaan}

Usia perusahaan didefinisikan sebagai jumlah tahun sejak perusahaan tersebut berdiri (Khan et al. 2013). Pengukuran usia perusahaan yang digunakan oleh Khan et al. (2013) menggunakan skala rasio sebagai berikut:

\section{Rumus 9. Pengukuran Usia Perusahaan}

FAGE $=$ Ln (The Number of Year Since The Firm's Inception)

\section{Likuiditas}

Likuiditas merupakan rasio untuk mengetahui kemampuan perusahaan dalam membayar kewajiban jangka pendek (Sulistyawati et al. 2016). Likuiditas diukur menggunakan skala rasio lancar yaitu dengan membandingkan aset lancar terhadap liabilitas lancarnya (Al-Ajmi et al. 2015). Pengukuran tersebut digambarkan sebagai berikut:

Rumus 10. Pengukuran Likuiditas

$$
\text { LIQ }=\frac{\text { Total Current Assets }}{\text { Total Current Liabilities }}
$$

\section{HASIL DAN PEMBAHASAN}

\section{Statistik Deskriptif}

Hasil pengujian statistik deskriptif untuk variabel yang digunakan dalam penelitian ini dapat dilihat pada Tabel 2 .

Tabel 2. Hasil Uji Statistik Deskriptif

\begin{tabular}{lrrrrr}
\hline \multicolumn{1}{c}{ Variabel } & $\mathbf{N}$ & \multicolumn{1}{c}{ Minimum } & Maksimum & \multicolumn{1}{c}{ Mean } & \multicolumn{1}{c}{ Std. Deviation } \\
\hline CSRRI & 297 & 0,12195 & 0,78049 & 0,3559967 & 0,12178354 \\
COMPWD & 297 & 0,00000 & 0,75000 & 0,1083545 & 0,17261379 \\
BSIZE & 297 & 2,00000 & 12,00000 & 4,1279461 & 1,81131769 \\
PUB & 297 & 0,00590 & 0,66930 & 0,2463261 & 0,14978765 \\
STA & 297 & 24,41416 & 33,19881 & 28,2012013 & 1,57843307 \\
ROE & 297 & $-1,24116$ & 1,43533 & 0,0947135 & 0,22989265 \\
\hline
\end{tabular}




\begin{tabular}{|c|c|c|c|c|c|}
\hline DTE & 297 & 0,04312 & 8,26133 & 1,1718804 & 1,24917901 \\
\hline FAGE & 297 & 1,60944 & 4,46591 & 3,5303890 & 0,42419396 \\
\hline LIQ & 297 & 0,36049 & 464,98442 & 4,1425667 & 26,93435869 \\
\hline
\end{tabular}

Sumber: Hasil Pengolahan Data SPSS 19 (2019)

Statistik deskriptif menunjukkan bahwa rata-rata jumlah pengungkapan tanggung jawab sosial perusahaan masih rendah, di bawah 50\%. Perusahaan di Indonesia masih tidak peduli pada pengungkapan tanggung jawab sosial perusahaan. Hal ini mungkin disebabkan karena komposisi wanita dalam dewan komisaris yang rendah dan profitabilitas yang rendah. Penalaran ini dapat dibuktikan dengan uji t. Sebelum uji t dilakukan, penelitian ini melakukan uji asumsi klasik terlebih dahulu.

\section{Uji Asumsi Klasik}

Hasil pengujian asumsi klasik untuk variabel yang digunakan dalam penelitian ini dapat dilihat pada Tabel 3 sampai dengan Tabel 5.

Tabel 3. Hasil Uji Multikolinearitas

\begin{tabular}{lccl}
\hline Variabel & Tolerance & VIF & Kesimpulan \\
\hline COMPWD & 0,952 & 1,051 & Tidak terjadi multikolinearitas \\
BSIZE & 0,528 & 1,895 & Tidak terjadi multikolinearitas \\
PUB & 0,915 & 1,093 & Tidak terjadi multikolinearitas \\
STA & 0,515 & 1,943 & Tidak terjadi multikolinearitas \\
ROE & 0,810 & 1,234 & Tidak terjadi multikolinearitas \\
DTE & 0,931 & 1,074 & Tidak terjadi multikolinearitas \\
FAGE & 0,859 & 1,165 & Tidak terjadi multikolinearitas \\
LIQ & 0,977 & 1,024 & Tidak terjadi multikolinearitas \\
\hline
\end{tabular}

Dependent variable: CSRRI

Sumber: Hasil Pengolahan Data SPSS 19 (2019)

Tabel 4. Hasil Uji Autokolerasi

\begin{tabular}{ccc}
\hline Variabel & Nilai Sig. & Kesimpulan \\
\hline RES_2 & 0,249 & Tidak terjadi autokorelasi \\
\hline
\end{tabular}

Sumber: Hasil Pengolahan Data SPSS 19 (2019) 
Tabel 5. Hasil Uji Heteroskedastisitas

\begin{tabular}{lcc}
\hline Variabel & Sig. & Kesimpulan \\
\hline COMPWD & 0,001 & Terjadi heteroskedastisitas \\
BSIZE & 0,748 & Tidak terjadi heteroskedastisitas \\
PUB & 0,008 & Terjadi heteroskedastisitas \\
STA & 0,001 & Terjadi heteroskedastisitas \\
ROE & 0,312 & Tidak terjadi heteroskedastisitas \\
DTE & 0,382 & Tidak terjadi heteroskedastisitas \\
FAGE & 0,293 & Tidak terjadi heteroskedastisitas \\
LIQ & 0,589 & Tidak terjadi heteroskedastisitas \\
\hline
\end{tabular}

Dependent Variable: ARES_1

Sumber: Hasil Pengolahan Data SPSS 19

\section{Pengujian Hipotesis}

Hasil uji t dalam penelitian ini ditunjukkan dalam Tabel 6.

Tabel 6. Hasil Uji t

\begin{tabular}{lccc}
\hline Model & B & Sig. & Keterangan \\
\hline (Constant) & $-0,464$ & 0,001 & \\
COMPWD & $-0,027$ & 0,441 & Ha1 tidak diterima \\
BSIZE & 0,013 & 0,004 & Ha2 diterima \\
PUB & 0,066 & 0,105 & Ha3 tidak diterima \\
STA & 0,030 & 0,000 & Ha4 diterima \\
ROE & 0,026 & 0,360 & Ha5 tidak diterima \\
DTE & $-0,010$ & 0,040 & Ha6 diterima \\
FAGE & $-0,027$ & 0,068 & Ha7 tidak diterima \\
LIQ & $-5,157 \mathrm{E}-5$ & 0,815 & Ha8 tidak diterima \\
\hline
\end{tabular}

Sumber: Hasil Pengolahan Data SPSS 19

Hasil uji t menunjukkan bahwa komposisi wanita dalam dewan komisaris (COMPWD) memiliki nilai signifikansi sebesar $0,441 \geq$ alpha 0,05 yang berarti komposisi wanita dalam dewan komisaris (COMPWD) tidak memiliki pengaruh terhadap pengungkapan tanggung jawab sosial perusahaan. Hasil ini berarti tidak menerima hipotesis alternatif pertama ( $\left.\mathrm{Ha}_{1}\right)$ yang menyatakan bahwa terdapat pengaruh komposisi wanita dalam dewan komisaris terhadap pengungkapan tanggung jawab sosial perusahaan. Minimnya komposisi wanita tersebut membuat apa yang hendak dilakukan wanita untuk pengungkapan tanggung jawab sosial perusahaan kalah kuat dengan argumen atau kebijakan dari komisaris pria seperti yang diungkapkan oleh Khan (2010).

Hasil uji t menunjukkan bahwa ukuran dewan komisaris (BSIZE) memiliki nilai signifikansi sebesar 0,004 < alpha 0,05 yang berarti ukuran dewan komisaris (BSIZE) memiliki pengaruh terhadap pengungkapan tanggung jawab sosial 
perusahaan. Hasil ini berarti menerima hipotesis alternatif kedua (Ha2) yang menyatakan bahwa terdapat pengaruh ukuran dewan komisaris terhadap pengungkapan tanggung jawab sosial perusahaan. Sesuai dengan teori keagenan, semakin banyak jumlah dewan komisaris maka akan semakin besar pengaruh mereka dalam mengawasi manajemen perusahaan termasuk dalam hal pengungkapan tanggung jawab sosial. Banyaknya dewan komisaris juga dapat memunculkan inovasi program sosial (Giannarakis 2013).

Hasil uji t menunjukkan bahwa kepemilikan publik (PUB) memiliki nilai signifikansi sebesar 0,105 $\geq$ alpha 0,05 yang berarti kepemilikan publik (PUB) tidak memiliki pengaruh terhadap pengungkapan tanggung jawab sosial perusahaan. Hasil ini berarti tidak menerima hipotesis alternatif ketiga ( $\left.\mathrm{Ha}_{3}\right)$ yang menyatakan bahwa terdapat pengaruh kepemilikan publik terhadap pengungkapan tanggung jawab sosial perusahaan. Kepemilikan publik tidak memiliki pengaruh karena masyarakat Indonesia belum peduli pada tanggung jawab sosial perusahaan (Deitiana 2015).

Hasil uji t menunjukkan bahwa ukuran perusahaan (STA) memiliki nilai signifikansi sebesar $0,000<$ alpha 0,05 yang berarti ukuran perusahaan (STA) memiliki pengaruh terhadap pengungkapan tanggung jawab sosial perusahaan. Hasil ini menerima hipotesis alternatif keempat ( $\mathrm{Ha}_{4}$ ) yang menyatakan bahwa terdapat pengaruh ukuran perusahaan (STA) terhadap pengungkapan tanggung jawab sosial perusahaan. Sesuai dengan teori legitimasi, semakin besar perusahaan maka akan semakin banyak stakeholder yang akan memperhatikan kegiatan mereka (pressure). Hal ini menyebabkan perusahaan akan semakin luas mengungkapkan tanggung jawab sosial mereka kepada berbagai stakeholder tersebut (Rudyanto 2018).

Hasil uji $\mathrm{t}$ menunjukkan bahwa profitabilitas (ROE) memiliki nilai signifikansi sebesar $0,360 \geq$ alpha 0,05 yang berarti profitabilitas (ROE) tidak memiliki pengaruh terhadap pengungkapan tanggung jawab sosial perusahaan. Hasil ini berarti tidak menerima hipotesis alternatif kelima (Ha5) yang menyatakan bahwa terdapat pengaruh profitabilitas (ROE) terhadap pengungkapan tanggung jawab sosial perusahaan. Besar kecilnya profitabilitas tidak mempengaruhi pengungkapan tanggung jawab sosial perusahaan karena pengungkapan tanggung jawab sosial perusahaan dapat memantapkan brand positioning mereka di masyarakat yang menjadi keuntungan tersendiri bagi perusahaan sehingga mereka berlomba untuk mengungkapkan tanggung jawab sosial perusahaan (Sulistyawati et al. 2016).

Hasil uji t menunjukkan bahwa leverage (DTE) memiliki nilai signifikansi sebesar 0,040 < alpha 0,05 yang berarti leverage (DTE) memiliki pengaruh terhadap pengungkapan tanggung jawab sosial perusahaan. Hasil ini berarti menerima hipotesis alternatif keenam ( $\mathrm{Ha}_{6}$ ) yang menyatakan bahwa terdapat pengaruh leverage (DTE) terhadap pengungkapan tanggung jawab sosial perusahaan. Pengaruh negatif menunjukkan bahwa pemegang saham lebih peduli pada pengungkapan tanggung jawab sosial perusahaan dibandingkan dengan kreditur (Khan et al. 2013).

Hasil uji t menunjukkan bahwa usia perusahaan (FAGE) memiliki nilai signifikansi sebesar $0,068 \geq$ alpha 0,05 yang berarti usia perusahaan (FAGE) tidak memiliki pengaruh terhadap pengungkapan tanggung jawab sosial perusahaan. 
Hasil ini berarti tidak menerima hipotesis alternatif ketujuh (Ha7) yang menyatakan bahwa terdapat pengaruh usia perusahaan terhadap pengungkapan tanggung jawab sosial perusahaan. Sesuai dengan teori legitimasi, perusahaan baru dan perusahaan lama sama-sama masih membutuhkan legitimasi dengan pengungkapan tanggung jawab sosial perusahaan agar dapat bertahan hidup (Rusmanto et al. 2014).

Hasil uji t menunjukkan bahwa likuiditas (LIQ) memiliki nilai signifikansi sebesar $0,815 \geq$ alpha 0,05 yang berarti likuiditas (LIQ) tidak memiliki pengaruh terhadap pengungkapan tanggung jawab sosial perusahaan. Hasil ini berarti tidak menerima hipotesis alternatif ke delapan ( $\mathrm{Ha}_{8}$ ) yang menyatakan bahwa terdapat pengaruh likuiditas terhadap pengungkapan tanggung jawab sosial perusahaan. Hal ini menunjukkan bahwa perusahaan telah menyisihkan uang untuk melakukan tanggung jawab sosial perusahaan dan pengungkapan tanggung jawab sosial perusahaan sehingga tinggi rendahnya likuiditas tidak berpengaruh pada sumber dana tanggung jawab sosial perusahaan (Al-Ajmi et al. 2015).

\section{SIMPULAN}

Ukuran dewan komisaris, ukuran perusahaan dan leverage memiliki pengaruh terhadap pengungkapan tanggung jawab sosial perusahaan. Komposisi wanita dalam dewan komisaris, kepemilikan publik, profitablitas, usia perusahaan dan likuiditas tidak berpengaruh terhadap pengungkapan tanggung jawab sosial perusahaan.

Penelitian ini memiliki keterbatasan sebagai berikut: (1) Periode penelitian yang terbatas dengan jangka waktu tiga tahun, yaitu tahun 2014 sampai dengan 2016 yang tidak dapat mewakili secara spesifik keadaan yang terjadi; (2) Penelitian ini belum memasukkan variabel independen lain yang mungkin memiliki pengaruh terhadap pengungkapan tanggung jawab sosial perusahaan; (3) Terdapat variabel yang mengandung heteroskedastisitas pada penelitian ini, yaitu varibel komposisi wanita dalam dewan komisaris, ukuran perusahaan, dan kepemilikan publik; (4) Untuk komposisi wanita dalam dewan komisaris, banyaknya jumlah 0 membuat hasil penelitian menjadi kurang spesifik dalam menentukan pengaruhnya terhadap pengungkapan tanggung jawab sosial.

Berdasarkan keterbatasan dalam penelitian ini, maka rekomendasi bagi penelitian selanjutnya adalah sebagai berikut: (1) Penelitian selanjutnya disarankan untuk memperpanjang periode penelitian agar dapat mewakili secara spesifik keadaan yang terjadi; (2) Menambahkan variabel independen lain yang mungkin dapat mempengaruhi pengungkapan tanggung jawab sosial perusahaan, seperti kepemilikan asing yang telah dibuktikan secara empiris oleh Haniffa dan Cooke (2005), Khan et al. (2013), Laksmitaningrum dan Purwanto (2013), serta Dewi dan Suaryana (2015) dan kepemilikan manajerial yang telah dibuktikan secara empiris oleh Anggraini (2006), Priantana dan Yustian (2011), serta Khan et al. (2013); (3) Mentransformasi model regresi dengan membagi model regresi dengan salah satu variabel independen yang digunakan dalam model tersebut untuk mengatasi masalah uji asumsi klasik heteroskedastisitas (Sekaran dan Bougie 2016, 148); (4) Menggunakan data perusahaan yang memang di dalamnya terdapat minimal satu 
anggota dewan komisaris wanita agar dapat mengetahui secara lebih spesifik pengaruhnya terhadap pengungkapan tanggung jawab sosial perusahaan atau menggunakan persentase komposisi.

\section{DAFTAR PUSTAKA}

Al-Ajmi, M., Abdullah Al-Mutairi, dan Nabi Al-Duwaila. (2015). Corporate Social Disclosure Practices in Kuwait, International Journal of Economics and Finance, Vol. 7, No. 9, 244-254.

Anggraini, F. dan Reni Retno. (2006). Pengungkapan Informasi Sosial dan FaktorFaktor yang Mempengaruhi Pengungkapan Informasi Sosial dalam Laporan Keuangan Tahunan (Studi Empiris pada Perusahaan yang Terdaftar di Bursa Efek Jakarta). Simposium Nasional Akuntansi IX, Padang, 23-26 Agustus.

Astuti, R.N.P., dan Rina Trisnawati. (2015). Pengaruh Karakteristik Perusahaan Manufaktur Terhadap Pengungkapan Corporate Social Responsibility (CSR) Serta Dampaknya Terhadap Reaksi Investor (Studi Pada Perusahaan Manufaktur di Bursa Efek Indonesia Periode Tahun 2010-2013), Seminar Nasional dan The 2nd Call for Syariah Paper, Universitas Muhammadiyah Surakarta, Surakarta, 13 Juni, 120-132.

Atakan, M. G. S, S. Burnaz and Y.I. Topcu. (2008). An Empirical Investigation of the Ethical Perceptions of Future Managers with a Special Emphasis on GenderTurkish Case, Journal of Business Ethics, No. 82, 573-586

Audriene, Dinda. 10 Februari (2017). Pertumbuhan Industri Melambat Jadi 4,4 Persen di 2016. CNNindonesia, (http://www.cnnindonesia.com/ekonomi /20170210082328-92-192545/pertumbuhan-industri-melambat-jadi-44per sen-di-2016/, 17 Maret 2017).

Badan Pemeriksa Keuangan Republik Indonesia. (2007). Laporan Pemeriksaan Atas Penanganan Semburan Lumpur Panas Sidoarjo. Jakarta

Badjuri, A. (2011). Faktor-Faktor Fundamental, Mekanisme Coorporate Governance, Pengungkapan Coorporate Social Responsibility (CSR) Perusahaan Manufaktur Dan Sumber Daya Alam di Indonesia Corporate Governance Mechanism, Fundamental Factors, Corporate Social Responsibility (CSR) Disclosure Of A Natural Resource And Manufactur Company In Indonesian, Dinamika Keuangan dan Perbankan, Vol. 3, No. 1: 38-54.

Carter D.A., Betty J. Simkins, W. Gary Simpson. (2003). Corporate Governance, Board Diversity, and Firm Value. The Financial Review 38, Oklahoma State University, 33-53. 
Chan, M.C., John Watson, dan David Woodliff. (2013). Corporate Governance Quality and CSR Disclosures. The Journal of Business Ethics, Springer Science+Business Media Dordrecht, September.

Deitiana, Tita. (2015). The Determinant of CSR Disclosure of Mining Industry Listed in Indonesia Stock Exchange. Asian Business Review, Vol. 5, No. 3: 141-148.

Dermawan, D. dan Tita Detiana. (2014). Faktor-faktor yang Mempengaruhi Pengungkapan Corporate Social Responsibility. Jurnal Bisnis dan Akuntansi, Vol.16, No.2: 158-165.

Dewi, N.P.M.S., dan I.G.N. Agung Suaryana. (2015). Pengaruh Profitabilitas dan Kepemilikan Asing Pada Pengungkapan Corporate Social Responsibility. EJurnal Akuntansi Universitas Udayana, 13.1: 84-98.

Dewi, S.P. dan Keni. (2013). Pengaruh Umur Perusahaan, Profitabilitas, Ukuran Perusahaan dan Leverage Terhadap Pengungkapan Tanggung Jawab Sosial Perusahaan. Jurnal Bisnis dan Akuntansi, Vol. 15, No. 1: 1-12.

Dowling, J. dan Jeffrey Pfeffer. (1975). Organizational Legitimacy: Social Values and Organizational Behaviour. Pacific Sociological Review, Vol. 18, No.1: 122-136.

Ghozali, Imam. (2016). Aplikasi Analisis Multivariete dengan Program IBM SPSS 23 Cetakan VIII. Semarang: Badan Penerbit Universitas Diponegoro.

Giannarakis, G. (2013). The Determinants Influencing The Extent of CSR Disclosure. International Journal of Law and Management, Vol.56, No.5: 393-416.

Gitman, Lawrence J. dan Chand J. Zutter. (2015). Principle of Managerial Finance, 14th Edition. England: Pearson Education.

Godfrey, Jayne, Allan Hodgson, Ann Tarca, Jane Hamilton, dan Scott Holmes. (2010). Accounting Theory, $7^{\text {th }}$ Edition. Australia: John Wiley and Sons.

Hadi, N. (2014). Corporate Social Responsibility. Yogyakarta: Penerbit Graha Ilmu.

Haniffa, R.M dan T.E. Cooke. (2005). The Impact of Culture and Governance on Corporate Social Reporting. Journal of Accounting and Public Policy, 24: 391 430.

Herawati, H. (2015). Corporate Governance, Karakteristik Perusahaan dan Pengungkapan Corporate Social Responsibility. Jurnal Riset Akuntansi dan Perpajakan, Vol. 2, No. 2: 203 - 217.

Hossain, M. dan Reaz, M. (2007). The Determinants and Characteristics of Voluntary Disclosure by Indian Banking Companies. Corporate Social Responsibility Environmental Management Journal, Vol. 14 No. 5:274-288. 
Indraswari, G.A.D., dan Ida Bagus Putra Astika. (2014). Pengaruh Profitabilitas, Ukuran Perusahaan, dan Kepemilikan Saham Publik Pada Pengungkapan CSR. E-Jurnal Akuntansi Universitas Udayana 9.3 : 816-828.

Jensen, Michael C. dan William H. Meckling. (1976). Theory of the Firm: Managerial Behaviour, Agency Cost, and Ownership Structure. Journal of Financial Economics, Vol. 3, No. 4: 305-360.

Kamil, A., dan Antonius Herusetya. (2012). Pengaruh Karakteristik Perusahaan Terhadap Luas Pengungkapan Kegiatan Corporate Social Responsibility. Media Riset Akuntansi, Vol. 2, No. 1: 1-17.

Kasali, Rhenald. (2005). Manajemen Public Relations. Jakarta: Ghalia Indonesia.

Kaspereit, T., Kerstin Lopatta dan Zoltan Matolcsy. (2016). Board Gender Diversity and Dimensions of Corporate Social Responsibility. Journal of Management and Sustainability, Vol. 6, No. 2: 50-66.

Khan, A., Mohammad Badrul Muttakin, dan Javed Siddiqui. (2013). Corporate Governance and Corporate Social Responsibility Disclosures: Evidence from an Emerging Economy. The Journal of Business Ethics, 114: 207-223.

Khan, Md. Habib-Uz-Zaman. (2010). The Effect of Corporate Governance Elements on Corporate Social Responsibility (CSR) Reporting Empirical Evidence From Private Commercial Banks Of Bangladesh. International Journal of Law and Management, Vol. 52, No. 2: 82-109.

Kiliç, M., Cemil Kuzey dan Ali Uyar. (2014). The Impact of Ownership and Board Structure on Corporate Social Responsibility (CSR) Reporting in The Turkish Banking Industry. Corporate Governance Journal, Vol. 15 No. 3: 357-374.

Komite Nasional Kebijakan Governance. (2006). Pedoman Umum Good Corporate Governance. Jakarta: KNKG.

Laksmitaningrum, C.F., dan Agus Purwanto. (2013). Analisis Pengaruh Karakteristik Perusahaan, Ukuran Dewan Komisaris dan Struktur Kepemilikan Terhadap Pengungkapan CSR (Studi Empiris Pada Perusahaan Manufaktur Yang Terdaftar Di Bursa Efek Indonesia Tahun 2009-2011). Diponegoro Journal of Accounting, Vol. 2, No. 3: 1-10.

Ling, C.T. dan Nigar Sultana. (2015). Corporate social responsibility: what motivates management to disclose? Social Responsibility Journal, Vol. 11 No. 3: 513-534.

Maiyarni R., Susfayetti, dan Misni Erwati. (2014). Pengaruh Profitabilitas, Ukuran Perusahaan, Likuiditas, dan Leverage Terhadap Pengungkapan Corporate Social Responsibility (CSR) Pada Perusahaan LQ-45 Yang Terdaftar di Bursa Efek Indonesia Periode 2009-2012. Jurnal Cakrawala Akuntansi, Vol. 6, No. 1: 
79-94.

Mayer, J.W. dan Rowan, B. (1977). Institutionalized Organizations: Formal Structure as Myth and Ceremony. American Journal of Sociology, Vol.83:340-363.

Nur, Marzully dan Denies Priantinah. (2012). Analisis Faktor-Faktor yang Mempengaruhi Pengungkapan Corporate Social Responsibility di Indonesia (Studi Empiris Pada Perusahaan Berkategori High Profile yang Listing di Bursa Efek Indonesia). Jurnal Nominal, Vol. I, No. I: 22-34.

Nurkhin, A. (2010). Corporate Governance Dan Profitabilitas, Pengaruhnya Terhadap Pengungkapan CSR Sosial Perusahaan. Jurnal Dinamika Akuntansi, Vol. 2, No. 1: 46-55.

O’Dovonan, G. (2002). Environmental Disclosure in The Annual Report: Extending the Aplicability and Predictive Power of Legitimacy Theory. Accounting, Auditing \& Accountability Journal, Vol. 15, No. 3:344-371.

Oktariani, N.W., dan Ni Putu Sri Harta Mimba. (2014). Pengaruh Karakteristik Perusahaan Dan Tanggung Jawab Lingkungan Pada Pengungkapan Tanggung Jawab Sosial Perusahaan. E-Jurnal Akuntansi Universitas Udayana, 6.3: 402418.

Oktariani, Wulantika. (2013). Pengaruh Kepemilikan Publik, Ukuran Dewan Komisaris, Profitabilitas dan Umur Perusahaan Terhadap Pengungkapan Tanggung Jawab Sosial Perusahaan. Jurnal Ilmiah Wahana Akuntansi, Vol. 8, No.2: 100-117.

Otoritas Jasa Keuangan Republik Indonesia. (2016). Peraturan Otoritas Jasa Keuangan Nomor 29/POJK.04/2016 Tentang Laporan Tahunan Emiten Atau Perusahaan Publik. Jakarta

Pamies, Dolors Seto. (2013). The Relationship between Women Directors and Corporate Social Responsibility. Corporate Social Responsibility and Environmental Management, Wiley Online Library.

Plorensia, A.P. dan Pancawati Hardiningsih. (2015). Pengaruh Agresivitas Pajak dan Media Eksplosure Terhadap Corporate Social Responsibility. Dinamika Akuntansi, Keuangan, dan Perbankan, Vol. 4, No. 2: 136 - 151.

Porter, M.E., dan Mark R. Kramer. (2006). The Link Between Competitive Advantage and Corporate Social Responsibility. Strategy and Society Harvard Business Review, Desember, 78-92.

Pradnyani, I.G.A.A., dan Eka Ardhani Sisdyani. (2015). Pengaruh Ukuran Perusahaan, Profitabilitas, Leverage, dan Ukuran Dewan Komisaris Pada Pengungkapan Tanggung Jawab Sosial Perusahaan. E-Jurnal Akuntasi 
Universitas Udayana, 11.2: 384-397.

Priantana, R.D., dan Ade Yustian. (2011). Pengaruh Struktur Good Corporate Governance Terhadap Pengungkapan Corporate Social Responsibility Pada Perusahaan Keuangan Yang Terdaftar di Bursa Efek Indonesia. Jurnal Telaah \& Riset Akuntansi, Vol. 4. No. 1: 65 - 78.

Puryati, Dwi. (2013). The Influence of Financial Performance and Institutional Ownership on Disclosure of Corporate Social Responsibility: Empirical Study of The Companies Listed on Indonesia Stock Exchange in 2012. Manajemen \& Bisnis Berkala Ilmiah, Vol. 12, No. 2: 173-186.

Rahayu, P. dan Indah Anisyukurlillah. (2015). Pengaruh Kepemilikan Saham Publik, Profitabilitas dan Media Terhadap Pengungkapan Tanggung Jawab Sosial. Accounting Analysis Journal, 4(3): 1-9.

Rahman, N.H.W.A., Mustaffa Mohamed Zain dan Norashfah Hanim Yaakop Yahaya Al-Haj. (2011). CSR Disclosures and Its Determinants: Evidence From Malaysian Government Link Companies. Social Responsibility Journal, Vol. 7, No. 2: 181-201.

Republik Indonesia. (2012). Peraturan Pemerintah Republik Indonesia Nomor 47 Tahun 2012 Tentang Tanggung Jawab Sosial dan Lingkungan Perseroan Terbatas. Jakarta.

Republik Indonesia. (2007). Undang-Undang Nomor 25 Tahun 2007 Tentang Penanaman Modal. Jakarta.

Republik Indonesia. (2007). Undang-Undang Nomor 40 Tahun 2007 Tentang Perseroan Terbatas. Jakarta.

Ross, S.A., Randolph W. Westerfield, Jeffrey F. Jaffe, dan Bradford D. Jordan. (2015). Corporate Finance: Core Principles and Applications Asia Global Edition. Singapore: Mc Graw-Hill Education.

Rudito, Bambang dan Melia Famiola. (2013). CSR (Corporate Social Responsibility). Bandung: Penerbit Rekayasa Sains.

Rudyanto, Astrid. (2018). The Effect of Internal and External Mechanism on Corporate Social Responsibility Disclosure. AFEBI Accounting Review, Vol 3 No 2, 47-61.

Rusmanto, T., Stephanus Remond Waworuntu, dan Valina Purnama Syahbandiah. (2014). The Impact of Corporate Governance on Corporate Social Responsibility Disclosure: Evidence from Indonesia. Proceedings Book of ICETSR, Malaysia. 377-385. 
Samsiyah, Eka., dan Kurnia. (2014). Pengaruh Profitabilitas, Likuiditas dan Leverage Terhadap Pengungkapan Tanggung Jawab Sosial Perusahaan. Jurnal Ilmu \& Riset Akuntansi, Vol. 3 No. 4: 1-14.

Santioso, L. dan Erline Chandra. (2012). Pengaruh Profitabilitas, Ukuran Perusahaan, Leverage, Umur Perusahaan, dan Dewan Komisaris Independen dalam Pengungkapan Corporate Social Responsibility. Jurnal Bisnis dan Akuntansi, Vol. 14, No. 1: 17 - 30.

Sari, R.A. (2012). Pengaruh Karakteristik Perusahaan Terhadap Corporate Social Responsibility Disclosure Pada Perusahaan Manufaktur Yang Terdaftar di Bursa Efek Indonesia. Jurnal Nominal, Vol. I No. I: 124-140.

Sekaran, Uma dan Roger Bougie. (2016). Research Methods for Business $7^{\text {th }}$ Edition. United Kingdom: John Wiley and Sons Ltd.

Septiana dan Fitria. (2014). Pengaruh Karakteristik Perusahaan Terhadap Corporate Social Responsibility Pada Perusahaan Manufaktur. Jurnal Ilmu \& Riset Akuntansi Vol. 3 No. 7: 1-20.

Siregar, S.V., dan Yanivi Bachtiar. (2010). Corporate social reporting: Empirical Evidence from Indonesia Stock Exchange. International Journal of Islamic and Middle Eastern Finance and Management, Vol. 3, No. 3: 241-252.

Sriayu, G.A.P.W., dan Ni Putu Sri Harta Mimba. (2013). Pengaruh Karakteristik Perusahaan Terhadap Corporate Social Responsibility Disclosure. E-Jurnal Akuntansi Universitas Udayana, Vol. 5, No.2: 326-344.

Smith, W., Wokutch, R., Harrington, K., \& Dennis, B. (2001). An examination of the influence of diversity and stakeholder role on corporate social orientation. Business and Society, Vol. 40, No.3: pp. 266-294

Subramanyam, K. R. (2014). Financial Statement Analysis $11^{\text {th }}$ Edition. New York: Mc Graw-Hill Education.

Suchman, M.C. (1995). Managing Legitimacy: Strategic and Institutional Approaches. Academy of Management Review, Vol. 20, No. 3: 571-610.

Sulistyawati, A.I., Rr. Lulus Prapti Nugroho Setiasih Surjanti, dan Dian Triyani. (2016). Pengungkapan Corporate Social Responsibility Pada Laporan Keuangan dan Determinasinya. Seminar Nasional IENACO - 2016, Universitas Muhammadiyah Semarang, 23-24 Maret, 467-475.

Sundarasen, S.D.D., Tan Je-Yen dan Nakiran Rajangam. (2015). Board Composition and Corporate Social Responsibility In An Emerging Market, Corporate Governance Journal, Vol. 16 No. 1: 35-53. 
Susilo, Priyo. 23 Februari 2016. BISNIS INDONESIA 23 Februari, Seksi Industri: Kontribusi Industri Manufaktur Melesat. Bisnis Indonesia, (http://koran.bisnis.com/read/20160223/244/521613/bisnis-indonesia23-februari-seksi-industri-kontribusi-industri-manufaktur-melesat, $\quad 17$ Maret 2017).

Tan, A., Desmiyawati Benni, dan Warda Liani. (2016). Determinants of Corporate Social Responsibility Disclosure and Investor Reaction, International Journal of Economics and Financial Issues, 6(S4) 11-17.

Tricker, Bob. (2015). Corporate Governance: Principles, Policies, and Practices $3^{\text {rd }}$ Edition. United Kingdom: Oxford University Press.

Trisnawati, Rina. (2014). Pengaruh Ukuran Perusahaan, Profitabilitas, Leverage, Ukuran Dewan Komisaris dan Kepemilikan Manajerial Terhadap Pengungkapan Corporate Social Responsibility (CSR) Industri Perbankan di Indonesia. Seminar Nasional dan Call For Paper, Program Studi AkuntansiFEB UMS, Surakarta, 25 Juni 2014.

Untoro, Dwi Arini dan Zulaikha. (2013). Pengaruh Karakteristik Good Corporate Governance (GCG) Terhadap Luas Pengungkapan Corporate Social Responsibility (CSR) Di Indonesia (Studi Empiris Pada Perusahaan Perbankan Yang Terdaftar Di BEI Tahun 2008-2011). Diponegoro Journal of Accounting Vol. 2, No. 2: 1-12.

Untung, B. (2014). CSR dalam Dunia Bisnis. Yogyakarta: Penerbit CV Andi Offset (Penerbit ANDI).

Utami, I.D., dan Rahmawati. (2010). Pengaruh Ukuran Perusahaan, Ukuran Dewan Komisaris, Kepemilikan Institusional, Kepemilikan Asing, Dan Umur Perusahaan Terhadap Corporate Social Responsibility Disclosure Pada Perusahaan Property dan Real Estate Yang Terdaftar di Bursa Efek Indonesia. Jurnal Akuntansi dan Manajemen, Vol. 21, No. 3: 297-306.

Wardhani, W.M., dan Fidelis Arastyo Andono. (2017). Implikasi Tanggung Jawab Sosial dan Lingkungan Terkait Potensi Dugaan Kejahatan Korporasi: Studi Content Analysis Pada PT Lapindo Brantas Inc. Jurnal Akuntansi Bisnis, Vol. 10 No. 1: 54-72.

Wartick, S.L., dan Mahon John F. (1996). Toward a Substantive Definition of the Corporate Issue Construct: A Review and Synthetis of the Literature. Business and Society, Vol. 33, No.3: 293-311.

Yuliana R., Bambang Purnomosidhi., Eko Ganis Sukoharsono. (2008). Pengaruh Karakteristik Perusahaan Terhadap Pengungkapan Corporate Social Responsibility (CSR) dan Dampaknya Terhadap Reaksi Investor. Jumal Akuntansi Dan Keuangan Indonesia, Vol. 5, No. 2: 245-276. 
Yusuf, Muhammad. (2011). Analisa Pengaruh Karakteristik Perusahaan Terhadap Tingkat Pengungkapan Tanggung Jawab Sosial Perusahaan Pada Perusahaan High Profile Yang Tercatat di Bursa Efek Indonesia Pada Tahun 2005-2007. Binus Business Review, Vol. 2 No. 1:571-583.

Zhang, J.Q., Hong Zhu, dan Hung-bin Ding. (2012). Board Composition and Corporate Social Responsibility: An Empirical Investigation in the Post Sarbanes-0xley Era. The Journal of Business Ethics, 114 : 381-392.

\section{LAMPIRAN}

Lampiran 1. Indeks Pengungkapan Tanggung Jawab Sosial Perusahaan

NO ITEMS

COMMUNITY INVOLVEMENT

\begin{tabular}{|c|c|}
\hline 1 & General philanthropy \\
\hline 2 & Participation in government social campaigns \\
\hline 3 & Community programs (health \& education) \\
\hline \multicolumn{2}{|c|}{ ENVIROMENTAL } \\
\hline 1 & Environmental policies \\
\hline 2 & Raw materials conservation \& recycling \\
\hline 3 & Environmental protection programmed \\
\hline 4 & Awards for environmental protection \\
\hline 5 & $\begin{array}{l}\text { Support for public/private action designed to protect the environmental and natural disaster } \\
\text { victims }\end{array}$ \\
\hline \multicolumn{2}{|r|}{ EMPLOYEE INFORMATION } \\
\hline 1 & Employees appreciation \\
\hline 2 & Recruitment problems \\
\hline 3 & Discussion of ways to overcome problems (evaluation) \\
\hline 4 & Employee welfare \\
\hline 5 & Employee benefits, bonuses \\
\hline 6 & Profit sharing schemes policy \\
\hline 7 & Number of employee \\
\hline 8 & Breakdown of employee by line of business (career development, rotation, cross assignment) \\
\hline 9 & Breakdown of employee by geographic area \\
\hline 10 & Categories of employee by functions \\
\hline 11 & Categories of employee by race \\
\hline 12 & Categories of employee by age \\
\hline 13 & Numbers of employees for 2 or more years \\
\hline 14 & Reason for changes in employee number \\
\hline 15 & General redundancy/ retrenchment information \\
\hline 16 & Information on accidents \\
\hline 17 & Cost of safety measures \\
\hline 18 & Health \& safety standards \\
\hline 19 & Corporate policy \\
\hline 20 & Nature of training \\
\hline 21 & Number of employees trained \\
\hline 22 & Amount spent on employees training \\
\hline 23 & Categories of employee trained \\
\hline \multicolumn{2}{|c|}{ PRODUCT OR SERVICE INFORMATION } \\
\hline 1 & Discussion of major types of products \\
\hline 2 & Pictures of major types of products \\
\hline 3 & Improvement in product quality \\
\hline 4 & Improvement in customer services \\
\hline 5 & Distribution of marketing network for products domestic market \\
\hline
\end{tabular}


Hasanah \& Rudyanto, Determinan Pengungkapan Corporate ...

\begin{tabular}{cl}
\hline 6 & Distribution of marketing network for products foreign market \\
\hline 7 & Customer awards/ratings received \\
\hline VALUE-ADDED INFORMATION \\
\hline 1 & Value-added statement \\
\hline 2 & Qualitative value-added statement \\
\hline 3 & Value-added data/ratios \\
\hline
\end{tabular}


EQUITY, Vol. 22, No.2, 2019, 215-238

Halaman ini sengaja dikosongkan untuk kepentingan penggenapan halaman 